\title{
MEDUSAHEAD INVASION ALONG UNIMPROVED ROADS, ANIMAL TRAILS, AND RANDOM TRANSECTS
}

\author{
Kirk W. Davies ${ }^{1,3}$, Aleta M. Nafus ${ }^{2}$, and Matthew D. Madsen ${ }^{1}$
}

\begin{abstract}
Medusahead (Taeniatherum caput-medusae [L.] Nevski), an exotic annual grass, is rapidly spreading and causing ecological damage across the western United States. Because this exotic plant occupies vast areas and because management resources are limited, it is critical that land managers prioritize where they direct treatment and monitoring efforts. Identifying where and by what means medusahead is spreading could provide valuable information to assist in determining where prevention and control efforts should be applied. We compared medusahead invasion levels along unimproved roads, animal trails, and random transects at 6 sites in southeastern Oregon to determine where medusahead was more common and to identify potential vectors for its spread. Medusahead was more common and its cover was greater along unimproved roads than along trails and random transects. Medusahead infestations were also larger along roads. Medusahead was more common along animal trails than along random transects, but differences were less evident. Our results suggest that medusahead spreads along roads. This outcome implies, though not conclusively, that vehicles may be one of the most important vectors for medusahead spread. Our results also suggest that animals may be a vector for medusahead dispersal; however, invasions were much more concentrated near roads than trails, suggesting that medusahead management along roads should receive higher priority. Medusahead invasion is not random across the landscape, and thus, control and monitoring efforts can be prioritized, based on potential vector pathways, to manage this invasive plant.
\end{abstract}

Resumen.-La Cabeza de Medusa (Taeniatherum caput-medusae [L.] Nevski), una hierba exótica anual, se está esparciendo rápidamente y está provocando daño ecológico en la región oeste de los Estados Unidos. Es esencial que los manejadores de las tierras prioricen hacia dónde dirigen los esfuerzos de tratamiento y seguimiento debido a las extensas áreas que ocupa esta planta exótica, y a la cantidad limitada de recursos disponibles para su manejo. El identificar dónde y de qué modo se esparce la Cabeza de Medusa podría proporcionar información valiosa para ayudar a determinar dónde deben aplicarse los esfuerzos de control y prevención. Comparamos los niveles de invasión de esta hierba a lo largo de caminos no mejorados, senderos de animales y transectos aleatorios en seis sitios del sureste de Oregon para determinar dónde fue más común la Cabeza de Medusa y para identificar los posibles vectores para su propagación. Descubrimos que la Cabeza de Medusa fue más común y su cobertura mayor en caminos no mejorados que en senderos y transectos aleatorios. Las infestaciones de Cabeza de Medusa también fueron extensas en los caminos. Esta hierba fue más común en senderos de animales que en ubicaciones aleatorias, pero las diferencias fueron menos evidentes. Nuestros resultados sugieren que la Cabeza de Medusa se esparce a lo largo de los caminos. Esto implica, aunque no de manera concluyente, que los vehículos pueden ser uno de los vectores más importantes para la propagación de esta hierba. Nuestros resultados también sugieren que los animales pueden ser un vector para la dispersión de la Cabeza de Medusa. Sin embargo, las invasiones de Cabeza de Medusa estuvieron mucho más concentradas cerca de los caminos que en los senderos, lo que sugiere que el manejo de dicha hierba en los caminos debe tener mayor prioridad. La invasión de Cabezas de Medusa no es aleatoria en el paisaje y, por lo tanto, los esfuerzos de control y de seguimiento pueden priorizarse con base en las rutas de los posibles vectores para manejar esta planta invasora.

Invasive plants are a serious concern in wildlands around the world (D'Antonio and Vitousek 1992, DiTomaso 2000, Mack et al. 2000) and threaten biodiversity and ecosystem function (Vitousek et al. 1997). Medusahead (Taeniatherum caput-medusae [L.] Nevski) is an exotic annual grass that is problematic in the western United States (Young 1992). Invasion by medusahead degrades wildlife habitat, decreases biodiversity, reduces livestock forage, and threatens ecosystem function (Davies and Svejcar 2008, Davies 2011). With medusahead's essentially unchecked spread across wildlands, its negative impacts are escalating. In fact, medusahead and other exotic annual grasses are collectively one of the greatest threats to the sagebrush ecosystem (Davies et al. 2011). Thus, there is an urgent need to limit the expansion of medusahead and other invasive plants through prevention and control

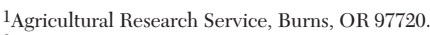

${ }^{2}$ Oregon State University, Eastern Oregon Agricultural Research Center, Burns, OR 97720.

${ }^{3}$ E-mail: kirk.davies@oregonstate.edu
} 
efforts (Davies and Johnson 2011). Considering the vast expanses threatened by medusahead invasion (Young 1992) and the limited resources available to address this issue, there is a need to make monitoring and management efficient by identifying areas where infestations are most probable.

Identifying where invasions are more common in wildlands could provide valuable information on what vectors are probably contributing to the spread of medusahead. This information would be critical in developing effective prevention strategies and prioritizing where monitoring for new infestations should be conducted. Knowing what vectors contribute to the dispersal of an invasive plant allows land managers to tailor management to most effectively reduce that plant's spread (Davies and Sheley 2007a).

Roads may act as corridors for the spread of invasive plants species, with vehicles potentially spreading seeds long distances (Masters and Sheley 2001, Flory and Clay 2006, Christen and Matlack 2009, Mortensen et al. 2009). However, most studies have been limited to maintained roads and thus have largely ignored unimproved roads. In the rural western United States, unimproved roads bisect large, otherwise generally inaccessible tracts of rangelands. Invasive species may also be spread along trails. Wells and Lauenroth (2007) reported that horses were a potentially important dispersal vector of exotic plants along recreational trails. Long, sharp, barbed awns on medusahead seeds are likely important morphological features that cause them to adhere to and be spread by animals and potentially vehicles (Monaco et al. 2005, Davies and Sheley 2007b). This adaptation of the seeds leads to the hypothesis that medusahead infestations are probably more common along roads and animal trails than in random locations. However, information on the abundance of medusahead infestations relative to roads, trails, and random locations is lacking.

The objectives of this study were to determine where medusahead infestation patches were more common and detail medusahead invasion characteristics along trails, unimproved roads, and random transects. This critical information will guide where management should focus on detecting new infestations and potentially where control efforts should be applied. We hypothesized that (1) medusahead is more frequent along potential vector pathways (roads and trails) than along random transects and (2) medusahead patches are larger and medusahead cover is greater along potential vector pathways than along random transects.

\section{Methods \\ Study Area}

The study was conducted across a 500,000ha area in southeastern Oregon in Harney County and the western half of Malheur County in the High Desert and Snake River Ecological Province (Anderson et al. 1998). Long-term average annual precipitation at weather stations near the study sites was 250-320 mm (OCS 2009). Study sites were located within 10-30 km of Juntura, Burns, Crane, Riley, Diamond, and Venator, Oregon. Elevation ranges from 1000 to $1450 \mathrm{~m}$ above sea level. Slopes and aspects were variable among and within sites. Plant communities were sagebrush (Artemisia Nutt.) steppe with various levels of medusahead invasion.

\section{Experimental Design}

A block design was used to evaluate the effect of location on medusahead invasion characteristics. Six $2 \times 2$-km sites (blocks) were included in the study. The maximum distance between sites was $110 \mathrm{~km}$. At each site, 3 locations were sampled: (1) road, (2) animal trail, and (3) random transect. Each location in each site was sampled using a 500-m transect. Sampling locations for both roads and trails were selected by starting in the middle of the site, and then an azimuth (in degrees) was determined by generating a random number between 1 and 360. The random azimuth was followed until a road or trail was located, then a coin was flipped to determine which direction to sample along the road or trail. Roads were unpaved and unimproved (i.e., "dirtroads") These roads were not bladed or leveled and did not have any materials added to them. These roads are the most common type of road across vast areas being invaded by medusahead. Animal trails were paths $\geq 15 \mathrm{~cm}$ wide that showed signs of animal use (tracks or feces). Trails were used mainly by domestic cattle, but wildlife also used them. Roads and animal trails were sampled with transects set parallel to them at $100 \mathrm{~cm}$ from their edge. 


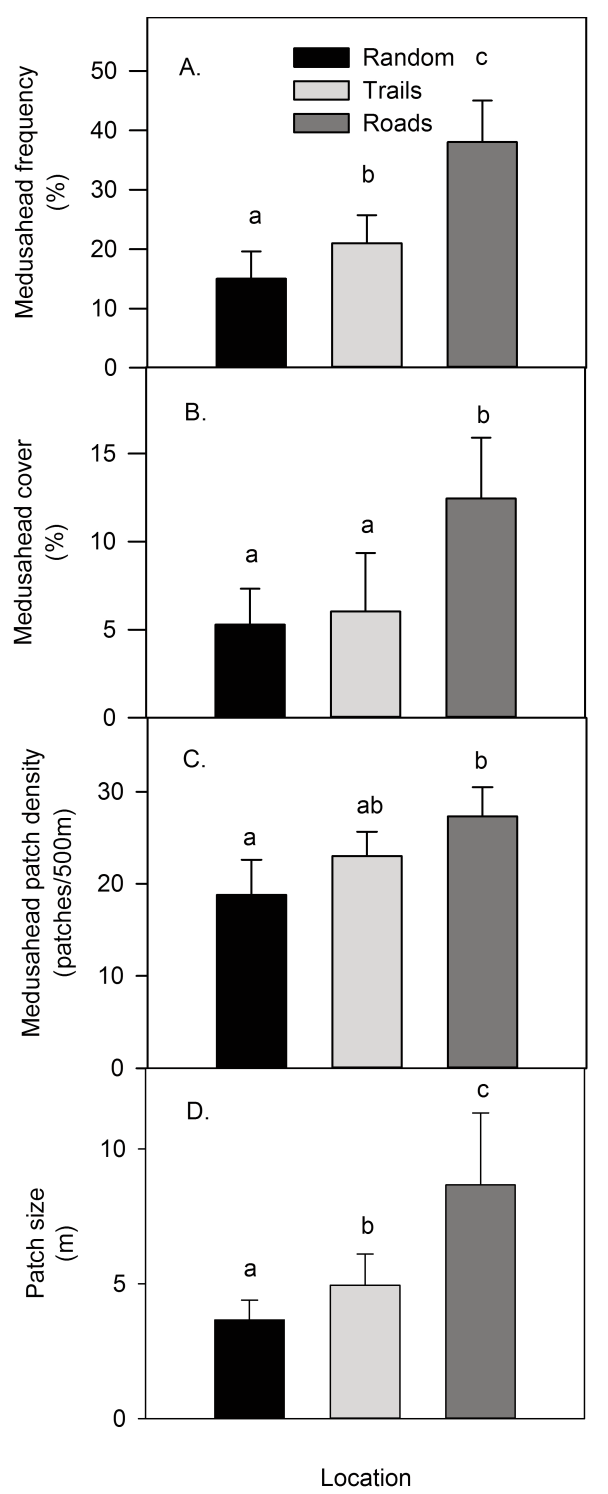

Fig. 1. Medusahead (A) frequency, (B) cover, (C) patch density, and (D) patch size along roads, animal trails, and random transects in sagebrush steppe plant communities in southeastern Oregon. Reported values are means with standard error bars. Different lowercase letters indicate significant differences $(P \leq 0.10)$ between sampling locations.

Random transects were established by starting in the center of the site and then determining a transect azimuth (in degrees) by generating a random number between 1 and 360. When trails, roads, or random transects intersected each other, a 10-m buffer around the intersection was not sampled. Intersect lengths not sampled were added to the end of the transect to ensure a 500-m sample.

\section{Measurements}

Each site was sampled in July of either 2010 or 2011. Medusahead presence or absence was recorded for every meter in a $10 \mathrm{~cm}$ $\times 100$-cm plot along each 500-m transect to determine frequency. Percent frequency was calculated by dividing the number of plots with medusahead by the total number of plots and then multiplying by 100 . Medusahead was considered present in each meter if at least one medusahead plant was rooted in the $10 \mathrm{~cm}$ $\times 100-\mathrm{cm}$ plot placed along the 500-m transect. Medusahead cover was measured using the line-intercept method (Canfield 1941) along the 500-m transect. Medusahead average patch size was the combined length of the patches bisected by the 500-m transect divided by the number of patches. Patches were considered individual patches if they were separated by $>100 \mathrm{~cm}$. Patch density was the number of individual patches located along the 500-m transect.

\section{Statistical Analyses}

Analysis of variance (ANOVA) with a block design using the PROC MIX method in SAS v.9.1 (SAS Institute Inc., Cary, NC) was used to compare medusahead invasion characteristics between the different locations. Sites were treated as blocks in the analyses. The appropriate covariance structures were determined by using Akaike's information criterion (Littell et al. 1996). Response variables were medusahead frequency, cover, density of patches, and patch size. Location (random transect, trail, and road) was considered the "treatment." Location means were separated using the least-squares means method in PROC MIX. Means of different locations were considered significantly different at $P \leq 0.10$. We selected this level of significance because we wished to reduce the likelihood of type II errors.

\section{Results}

Medusahead frequency (the number of meters per transect that contained medusahead) varied by location (Fig. 1A; $P=0.012$ ). Medusahead frequency was higher along roads than along trails $(P=0.003)$ and random transects $(P<0.001)$. Medusahead frequency was 
3-fold more along roads than along random transects. Medusahead frequency was also greater along trails compared to random transects $(P=0.083)$. Medusahead cover varied among the locations (Fig. 1B; $P<0.001$ ). Medusahead cover was greater along roads compared to trails $(P=0.012)$ and random transects $(P=0.007)$. Roads had 2-fold more medusahead cover than the other locations. Trails and random transects did not vary in medusahead cover $(P=0.732)$. The density of medusahead patches differed among the locations (Fig. 1C; $P=0.087$ ). Medusahead patch density was 1.5 -fold greater along roads than along random transects $(P=0.031)$. Patch density did not differ between random transects and trails or between trails $(P=0.247)$ and roads $(P=0.230)$. Medusahead patch size varied by location (Fig. 1D; $P=0.030$ ). The average medusahead patch size along roads was 1.8- and 2.4-fold greater than patches along trails and random transects, respectively $(P=0.015$ and $P<0.001$, respectively). Patches along trails were 1.4-fold larger than patches along random transects $(P=0.079)$.

\section{Discussion}

Medusahead was more common and occupied a larger part of plant communities along roads than along trails and random transects. Medusahead was also more common along trails than along random transects; however, the differences were not as evident. A lack of difference in medusahead cover values between trails and random locations suggests that the influence of medusahead in the plant communities probably did not vary between these 2 locations. However, in the future, medusahead may become more of a problem along trails because it is more common there than at random locations. And the more common medusahead is at a site, the more likely it is to have seeds in the right locations to take advantage of any safe sites that become open.

Our results suggest that roads are an important pathway for the spread of medusahead. Similarly, Christen and Matlack (2009) reported that roads are often a conduit for the spread of invasive plants. In agreement with our results, Mortensen et al. (2009) concluded that roads facilitated invasive plant spread through forested lands in Maryland. The presence and high cover of medusahead along roads in our study suggest that vehicles may be an important vector for the spread of medusahead; however, empirical testing will be needed to confirm this idea. Long, barbed awns on medusahead seeds probably facilitate transport by vehicles (Monaco et al. 2005, Davies and Sheley 2007b). However, the likelihood of dispersal of medusahead by vehicles is probably facilitated by more factors than seed characteristics alone. Clayey soils, where medusahead invasion is often successful (Young 1992), adhere to vehicles when moist. Thus, clayey soils embedded with medusahead seeds may attach to vehicles and be transported great distances. Long-distance transport of invasive plant seeds by vehicles is routine along roadways (Lippe and Kowarik 2007). Roads also often create habitat for invasive plants to colonize (Christen and Matlack 2009); however, the results of our study are probably at least in part due to the transport of seeds. The roads in the study area were not maintained, and we sampled $100 \mathrm{~cm}$ from the road edge, thus reducing the influence of roads on habitat. However, we cannot conclude that favorable habitat along roads did not contribute to the patterns of invasion we observed.

Animals may also be an important vector for the transport of medusahead seeds. Long, barbed awns on medusahead seeds probably adhere to animals' coats when the animals travel through infestations. Seeds with hooks, barbs, or awns are often transported by animals (Shmida and Ellner 1983, Sorensen 1986). However, differences in medusahead invasion characteristics between trails and roads suggest that vehicles possibly contribute more than animals to the spread of medusahead in our study area. However, because our study was observational, we cannot conclude indubitably that vehicles spread medusahead more than animals. Another important note is that vehicles and animals are not restricted to roads and trails, respectively. All-terrain vehicle tire tracks were observed in off-road locations in the study area several times during the duration of the study. Thus, vehicles and animals may contribute to medusahead spread at random locations.

Roads and animal trails are not randomly located across environmental heterogeneous landscapes. They occur in specific areas selected by animals or humans. For example, livestock trails in pastures are less steep than the mean 
slope of the pasture (Ganskopp et al. 2000). Therefore, the environment may be different at these locations than at random locations across the landscape. Environmental differences between these locations may contribute to differences in medusahead invasion characteristics. Regardless, our data demonstrate that areas of concentrated vector movement (i.e., roads and trails) have increased medusahead presence and cover, whether due to habitat, vectors, or, more likely, their combined effect.

This study links potential vector pathways with medusahead invasion in the sagebrush steppe ecosystem. Utilization of these data and other significant vector pathways by use of GIS and remote sensing technology could aid in modeling the dispersal of medusahead across heterogeneous landscapes. To aid in this research, effort should be directed toward understanding how vector pathways in this study are influenced by various ecological site characteristics, such as soil type, topography, and vegetation type. Integration of these kinds of variables should improve models and allow land managers to predict expansion of invasive plants over larger spatial and temporal scales (Holst et al. 2007, Freckleton and Stephens 2009).

\section{Conclusions}

Medusahead invasion is not random across the landscape; it is more common along vector pathways, and management should focus on reducing its spread along these pathways. Our results suggest that vehicles may be one of the most important vectors for medusahead spread; however, environmental differences between road locations and other locations may also be a contributing factor. Regardless, infestations along roads should be a priority for control. Reducing the contact between medusahead seeds and vehicles may be a mechanism for reducing the spread of medusahead. In areas where controlling the entire medusahead infestation is not feasible, controlling medusahead along roads may be a less expensive option to limit spread into noninvaded areas. Controlling medusahead in areas where animals concentrate should also be a priority. The results of this study also suggest that monitoring for new medusahead infestations should focus along roads and trails. Though not evaluated in this study, other vector pathways (e.g., waterways, wind patterns, etc.) may also need to be included as management priorities. Medusahead management can be improved by focusing on potential vector pathways (roads and trails) and recognizing that these, and potentially other pathways, should be a priority for monitoring and control efforts to limit the spread of medusahead.

\section{ACKNOWLEDGMENTS}

This research was supported by the Eastern Oregon Agricultural Research Center, a cooperative between USDA Agricultural Research Service and Oregon State University. We thank Drs. Brenda Smith and Dave Ganskopp for reviewing earlier versions of this manuscript. We also appreciate the constructive reviews by the associate editor and anonymous reviewers.

\section{Literature Cited}

Anderson, E.W., M.M. Borman, and W.C. Krueger. 1998. The ecological provinces of Oregon: a treatise on the basic ecological geography of the state. Oregon Agricultural Experiment Station, Corvallis, OR. $138 \mathrm{pp}$.

CANField, R.H. 1941. Application of the line interception method in sampling range vegetation. Journal of Forestry 39:388-394.

Christen, D.C., and G.R. Matlack. 2009. The habitat and conduit function of roads in the spread of invasive plant species. Biological Invasions 11:453-465.

D’Antonio, C.M., And P.M. Vitousek. 1992. Biological invasions by exotic grasses, the grass/fire cycle, and global change. Annual Reviews in Ecology and Systematics 23:63-87.

Davies, K.W. 2011. Plant community diversity and native plant abundance decline with increasing abundance of an exotic annual grass. Oecologia 167:481-491.

Davies, K.W., C.S. Boyd, J.L. Beck, J.D. Bates, T.J. SvejCAR, AND M.A. GREGG. 2011. Saving the sagebrush sea: an ecosystem conservation plan for big sagebrush plant communities. Biological Conservation 144:2573-2584.

DaviEs, K.W., AND D.D. Johnson. 2011. Are we "missing the boat" on preventing the spread of invasive plants in rangelands. Invasive Plant Science Management $4: 166-171$.

Davies, K.W., and R.L. Sheley. 2007a. A conceptual framework for preventing the spatial dispersal of invasive plants. Weed Science 55:178-184.

$2007 \mathrm{~b}$. Influence of neighboring vegetation height on seed dispersal: implications for invasive plant management. Weed Science 55:626-630.

Davies, K.W., and T.J. SvejCar. 2008. Comparison of medusahead-invaded and noninvaded Wyoming big sagebrush steppe in southeastern Oregon. Rangeland Ecology and Management 61:623-629.

DiTomaso, J.M. 2000. Invasive weeds in rangelands: species, impacts, and management. Weed Science $48: 255-265$ 
Flory, S.L., AND K. Clay. 2006. Invasive shrub distribution varies with distance to roads and stand age in eastern deciduous forests in Indiana, USA. Plant Ecology 184:131-141.

Freckleton, R.P., and P.A. Stephens. 2009. Predictive models of weed population dynamics. Weed Research 49:225-232.

Ganskopp, D., R. Cruz, and D.E. Johnson. 2000. Leasteffort pathways?: a GIS analysis of livestock trails in rugged terrain. Applied Animal Behavior Science 68:179-190.

Holst, N., I.A. Rasmussen, and L. Bastianns. 2007. Field weed population dynamics: a review of model approaches and applications. Weed Research 47:1-14.

LiPPE, M.V.D., AND I. KoWARIK. 2007. Long-distance dispersal of plants by vehicles as a driver of plant invasions. Conservation Biology 21:986-996.

Littell, R.C., G.A. Milliken, W.W. Stroup, and R.D. WOLFINGER. 1996. SAS system for mixed models. SAS Institute, Inc., Cary, NC. 663 pp.

Mack, R.N., D. Simberloff, W.M. Lonsdale, H. Evans, M. Clout, and F.A. Bazzaz. 2000. Biotic invasions: causes, epidemiology, global consequences, and control. Ecological Applications 10:689-710.

Masters, R.A., And R.L. Sheley. 2001. Principles and practices for managing rangeland invasive plants. Journal of Range Management 54:502-517.

Monaco, T.A., T.M. Osmond, and S.A. Dewey. 2005. Medusahead control with fall- and spring-applied herbicides in northern Utah foothills. Weed Technology 19:653-658.

Mortensen, D.A., E.S.J. Rauschert, A.N. Nord, and B.P. Jones. 2009. Forest roads facilitate the spread of invasive plants. Invasive Plant Science and Management 2:191-199.

[OCS] Oregon Climate Service. 2009. Oregon Climate Service [online]. Strand Hall Room 326, Oregon State University, Corvallis, OR; [cited 1 September 2009]. Available from: http://www.ocs.oregonstate.edu/

Shmida, A., AND S. ElLner. 1983. Seed dispersal on pastoral grazers in open Mediterranean chaparral, Israel. Israel Journal of Botany 32:147-159.

Sorensen, A.E. 1986. Seed dispersal by adhesion. Annual Reviews in Ecology and Systematics 17:443-463.

Vitousek, P.M., C.M. D’Antonio, L.L. Loope, M. RejMANEK, AND R. WESTBRoOKs. 1997. Introduced species: a significant component of human-caused global change. New Zealand Journal of Ecology 21:1-16.

WeLLS, F.H., AND W.K. LAUENROTH. 2007. The potential for horses to disperse alien plants along recreational trails. Rangeland Ecology and Management 60:574-577.

YounG, J.A. 1992. Ecology and management of medusahead (Taeniatherum caput-medusae ssp. asperum [Simk.] Melderis). Great Basin Naturalist 52:245-252.

Received 28 June 2012 Accepted 16 November 2012 